\title{
Evaluation of a Peer Network-Based Sexual Risk Reduction Intervention for Men in Beer Halls in Zimbabwe: Results from a Randomized Controlled Trial
}

\author{
Katherine Fritz · Willi McFarland · Robert Wyrod - Charles Chasakara • \\ Knox Makumbe • Admire Chirowodza • Chamunorwa Mashoko • \\ Timothy Kellogg • Godfrey Woelk
}

Published online: 5 March 2011

(c) The Author(s) 2011. This article is published with open access at Springerlink.com

\begin{abstract}
While much emphasis has been placed on involving men in AIDS prevention in sub-Saharan Africa, there remain few rigorously evaluated interventions in this area. A particularly appealing point of intervention is the sexual risk behavior associated with men's alcohol consumption. This article reports the outcomes of The Sahwira HIV Prevention Program, a male-focused, peer-based intervention promoting the idea that men can assist their friends in avoiding high-risk sexual encounters associated with alcohol drinking. The intervention was evaluated in a randomized, controlled trial (RCT) implemented in 24 beer halls in Harare, Zimbabwe. A cadre of 413 male beer hall
\end{abstract}

\author{
K. Fritz \\ International Center for Research on Women, \\ Washington, DC, USA \\ W. McFarland $(\bowtie) \cdot$ T. Kellogg \\ San Francisco Department of Public Health, 25 Van Ness \\ Avenue, San Francisco, CA 94102-6033, USA \\ e-mail: Willi.McFarland@sfdph.org \\ W. McFarland \\ Department of Epidemiology and Biostatistics, University \\ of California, San Francisco, San Francisco, CA, USA \\ R. Wyrod \\ Women's Studies Department, University of Michigan, \\ Ann Arbor, MI, USA \\ C. Chasakara - K. Makumbe - A. Chirowodza - C. Mashoko \\ The Harare Beer Hall Intervention, Harare, Zimbabwe \\ G. Woelk \\ Department of Community Medicine, University of Zimbabwe, \\ Harare, Zimbabwe \\ G. Woelk \\ RTI International, Research Triangle Park, NC, USA
}

patrons ( $\sim 20 \%$ of the patronage) was trained to assist their male peers within their friendship networks. Activities included one-on-one interactions, small group discussions, and educational events centering on the theme of men helping their male friends avoid risk. Venues were randomized into 12 control versus 12 intervention beer halls with little cross-contamination between study arms. The penetration and impact of the intervention were assessed by pre- and post-intervention cross-sectional surveys of the beer hall patronage. The intervention was implemented with a high degree of fidelity to the protocol, with exposure to the intervention activities significantly higher among intervention patrons compared to control. While we found generally declining levels of risk behavior in both study arms from baseline to post-intervention, we found no evidence of an impact of the intervention on our primary outcome measure: episodes of unprotected sex with nonwife partners in the preceding 6 months (median 5.4 episodes for men at intervention beer halls vs. 5.1 among controls, $P=0.98$ ). There was also no evidence that the intervention reduced other risks for HIV. It remains an imperative to find ways to productively engage men in AIDS prevention, especially in those venues where male bonding, alcohol consumption, and sexual risk behavior are intertwined.

Keywords Beer halls $\cdot$ Zimbabwe $\cdot$ Men $\cdot$ Alcohol $\cdot$ HIV

\section{Introduction}

For more than a decade, repeated calls have been made to involve heterosexual men in AIDS prevention [1-7], especially in sub-Saharan Africa where research has connected HIV transmission to men's sexual violence against 
women, men's multiple and concurrent sexual partnerships, men's dominant roll over reproductive decision making, and men's control over condom use and safe-sex practices [8-12]. However, conventional prevention strategies have been criticized for framing heterosexual men only as transmitters of HIV and failing to conceptualize how men could be active agents in AIDS prevention [13]. High levels of HIV transmission within serodiscordant couples also highlight the need to engage men in couples-oriented prevention, especially within longer-term partnerships [14-17]. In addition, the rollout of male circumcision as a form of AIDS prevention has underscored the importance of working with men to ensure circumcision does not lead to increased sexual risk behavior or "risk compensation" [18]. While innovative programs that engage men do now exist in several African countries [19, 20], there remain very few rigorously evaluated interventions focused on involving African men in HIV prevention [21-23].

Peer-oriented interventions hold particular promise for engaging men in AIDS prevention. Research has shown that social interactions between men are central to masculinity, with men seeking confirmation from their male peers in their attempts to live up to normative notions of manhood [24]. Such male-male bonds also strongly influence men's heterosexual relationships, with men competing for status among their male peers in part through their sexual relations with women $[25,26]$. Peer-focused interventions might harness such male bonding in constructive ways and encourage men to work with their male peers to promote AIDS prevention. Strategies focused on training "popular opinion leaders" as peer educators have shown some success in changing HIV-related risk behaviors in widely varying social contexts [27-30].

Male-focused peer interventions can also exploit existing venues where male-male social interaction typically occurs. In Zimbabwe, beer halls are one such venue. Beer halls are a widespread communal institution in Zimbabwe where drinking alcohol is a central part of social life for many men. Beer halls are patronized overwhelmingly by men and characterized by shared drinking of inexpensive beer, working class patronage, and a loyal clientele drawn from the immediate neighborhood. With spacious indoor and outdoor seating areas, beer halls can accommodate several hundred men at a time. Their importance as sites for interventions is further enhanced because alcohol is consumed at these venues. There is now much evidence that alcohol use is associated with HIV infection in east and southern Africa, with beer hall attendance also linked to risk of infection [31-35]. Beer halls, therefore, provide opportunities to intervene in those processes of male-male social interaction where alcohol consumption and HIV risk converge-making these venues key sites for AIDS prevention interventions involving men.
These factors motivated us to design a male-centered HIV prevention program in beer halls in Zimbabwe, a country which had one of the highest HIV prevalence in the world [36]. We developed a novel male-focused, peer-led intervention called The Sahwira HIV Prevention Program. The intervention centered on the Zimbabwean cultural concept of the sahwira, a particularly close and trusted friend. The Sahwira HIV Prevention Program promoted the idea that men can and should take responsibility for their friends' well-being by assisting each other to avoid highrisk sexual encounters associated with drinking at the beer hall. Here we report the results of a randomized, controlled trial (RCT) of The Sahwira HIV Prevention Program with men attending beer halls in Harare, Zimbabwe.

\section{Methods}

\section{Study Design and Study Subjects}

The study was conducted from 2002 to 2007 in beer halls located in low-income, residential neighborhoods of Harare, Zimbabwe. There were 56 beer halls located in the city of Harare in 2002. We chose 43 in which to conduct a preliminary or pre-baseline survey followed 1 year later by a baseline or pre-intervention survey. Three of the venues closed after the pre-baseline survey and thus were not included in the baseline survey. Inclusion criteria for beer halls were being located in a residential area and not adjacent to large markets or public transport hubs that could contribute to cross-contamination between beer halls after randomization. At pre-baseline and baseline, we collected information on men's beer hall attendance patterns, including patronage of multiple venues. Based on these data, we selected 24 of the initially surveyed 40 beer halls with the least amount of cross-patronage and randomly assigned them to 12 intervention and 12 control or comparison conditions using a random numbers table.

\section{Pre-Baseline and Baseline Survey Procedures and Measures}

We completed a pre-baseline seroprevalence and behavior survey in 2003 and repeated the survey in 2004. These surveys assessed time trends in HIV prevalence and risk behavior in advance of the intervention, determined comparability and stability of baseline characteristics over time, and explored potential for cross-contamination between beer halls after randomization. To obtain a representative sample of male beer hall patrons for the surveys, we adapted time-location sampling (TLS), a spatial-temporal method developed for recruitment of subjects attending drinking establishments and other diverse venues 
[37-39]. The method entailed (1) constructing a comprehensive sampling frame, in this case the beer halls chosen for inclusion; (2) creating a calendar of 4-h recruitment events; (3) randomly selecting beer halls to fill each calendar event; and (4) assessing the eligibility of every third man entering an intercept zone located at the beer hall entrance. The spatial-temporal sampling frame was constructed such that $70 \%$ of recruitment events took place during peak patronage periods (Friday evenings, Saturdays and Sundays) and 30\% during slow to moderate periods (weekday evenings). Eligibility criteria were being male, 18 years of age and older, a patron of the beer hall where recruited, sober, and being enumerated as one of every three people to cross the predetermined intercept zone at the entrance of the beer hall during the sampling period after a randomly chosen starting time. Eligible participants provided written informed consent, completed an interviewer-administered behavioral questionnaire, underwent HIV pre-test counseling, and had blood drawn for HIV testing. Informed consent, interview, blood draw, and counseling procedures took place in a mobile van parked near the beer hall entrance. Blood samples were screened for HIV antibody by HIV $1 / 2 \mathrm{gO}$ enzyme immunoassay (EIA) (Abbott Laboratories, Abbott Park, IL) and confirmed by a Dipstick rapid HIV assay (Pacific Biotech Co., Ltd., Bangkok, Thailand). Indeterminate results were resolved using Biotest EIA (Biotest Diagnostics Corp., Denville, NJ). At the time of the blood draw and pre-test counseling, participants were encouraged, but not required, to make an appointment to receive their HIV test results. Test results, post-test counseling, and referral to post-test care and support services were provided by our study staff.

Behavioral measures, including the primary outcome and several indicators of HIV-related risk, were collected through an interviewer administered, standardized questionnaire. The questionnaire included demographic characteristics, patterns of beer hall attendance and alcohol use, partner-by-partner sexual behavior in the previous 6 months, self-reported STI symptoms, patterns of peer influence on sexual risk behavior, knowledge about HIV, and previous exposure to HIV prevention materials or activities at the bars. Details of the measures, development, validation, and previous applications of the instrument have been published previously [17, 32]. The questionnaire was co-developed in Shona and English, forward and backward translated, field tested, and revised incorporating feedback from the current and previous studies of the target population [17, 32]. For sexual risk behavior measures, the approach was to collect information on each individual sexual partner for up to seven partners in the preceding 6 months. Each partner was self-described by type and classified into the categories of wife (including multiple wives in polygamous marriages and common law and formal wives according to civil, religious, and customary criteria), steady partner (by self-description), casual partner (not wives or steady partners but with whom sex occurred more than once), one off partners (with whom sex was only one time, but with whom no cash for sex was exchanged), and commercial partners (with whom cash was given for sex). For each partner, we elicited counts of the episodes of sexual contact and condom use with each episode over the last 6 months, and whether condoms were used at the last episode of unprotected sex while intoxicated. We examined sexual risk behavior by each partner type separately, by combining all partner types, and by combining all non-wife partner types. We also classified men as having no sex with any partners in the last 6 months and married and having no other partners. An 8-point factual knowledge score was also collected composed of recognizing modes of transmission, means of preventing HIV, and dispelling common myths about HIV. We also recorded whether men had previously tested for HIV.

\section{Intervention Procedures}

Following the baseline survey, 24 beer halls were selected based on their low levels of cross-patronage. Twelve were randomly assigned to the intervention condition and twelve to the comparison condition.

Comparison Condition Procedures Beer halls in the comparison arm of the study received a basic package of HIV prevention materials consistent with what was available in Zimbabwe at the time the study intervention took place. This included a steady supply of condoms for sale behind the bar and condom advertisements within the beer hall. We also displayed HIV prevention posters developed by the National AIDS Control Programme, ensuring that none of the posters portrayed prevention themes or slogans similar to those of the intervention.

Intervention Condition Procedures Intervention beer halls received the same basic package of intervention materials and services as comparison beer halls. In addition, we implemented the elements of The Sahwira HIV Prevention Program. The intervention focused on a cadre of 413 male beer hall patrons who volunteered to become Sahwira peer educators. To recruit peer educators, study staff circulated at the beer halls distributing promotional brochures and talking to patrons about the Sahwira HIV Prevention Program. To further promote the theme of friends assisting each other to reduce HIV risk behavior, peer educators were recruited as dyads-pairs of friends who regularly attended the beer hall together. The criteria for becoming a peer educator were being 18 years or older, volunteering along with a good friend who was also at least 
18 years old and a patron of the same beer hall, attending the beer hall at least eight times per month, being available to complete the three-day training and subsequently volunteer for a 15-month period. Because the recruitment process resulted in an over-enrollment of interested beer hall patrons, names were entered into a lottery and a public drawing was held at each beer hall as part of an HIV awareness event. Individuals chosen in the public drawing were invited to attend the training.

Peer educators received a three-day intensive training and 26 follow-up support meetings at their beer halls over a 15-month period. The three-day training curriculum included 14 sessions. Each session addressed one or more elements of the Information-Motivation-Behavioral Skills (IMB) behavior change theory [40, 41]. Subsequent support sessions were guided by a curriculum that further elaborated on material introduced in the initial training. The training and follow-up support of Sahwira peer educators was provided by eight full-time study staff members. The number of Sahwira educators recruited and trained was guided by the Diffusion of Innovation Theory [42, 43]. We determined the number of Sahwira educators to enroll by counting the number of men attending beer halls at peak attendance periods over a 1 month period, averaging the figures, and calculating how many peer educators would represent $20 \%$ of the peak patronage at each beer hall. We then adjusted the number upward by a relative $40 \%$ ( $8 \%$ absolute) in order to compensate for expected attrition over the course of the 15 -month intervention period. Sahwira peer educators received no monetary compensation for their effort; however, we did provide each educator with non-monetary incentives including certificates, a bag and cap printed with the intervention name and logo, and career development workshops.

Sahwira peer educator activities in beer halls included facilitating one-on-one and small-group discussions to promote HIV knowledge and risk reduction, organizing beer hall-wide awareness events, disseminating the Sahwira peer support theme by teaching beer hall patrons how to intervene with their friends when they saw a high risk situation unfolding, disseminating accurate information about condoms, providing demonstrations of correct condom use, and assisting beer hall managers to maintain an adequate supply of condoms for sale.

\section{One Year Follow-Up Assessment of Risk Behavior}

At the close of the 15-month intervention, we conducted a post-intervention assessment survey using the same methods and measures as the pre-baseline and baseline surveys; however, we added survey questions on intervention exposure, including awareness of the intervention theme, recognition of the intervention logo, recall of intervention messages, number of peer educators known to the patron, and exposure to intervention activities such as condom demonstrations, small group or one-on-one discussions, or special events. We also included questions about exposure to false materials or activities in order to assess levels of acquiescence bias.

\section{Analyses}

The analysis approach uses the beer hall as the unit of statistical power and evaluation because the unit of randomization was the beer hall, the intervention was delivered at the level of the beer hall, and the point for determining impact of the intervention was the patronage of the beer hall. Therefore the effective $N$ was 24 (i.e., 12 intervention vs. 12 control beer halls). Data were recorded at the individual level; however, for each variable, we examined percentages (e.g., percent currently married), medians, and means (e.g., age, number of partners, episodes of unprotected sex with non-spouse partners) for the patrons of each beer hall. Thus, each variable had 24 values corresponding to the levels at each beer hall. Comparisons of the percentages or median values between the intervention and control beer halls (12 vs. 12) were made using the non-parametric Wilcoxon rank sum test.

We first assessed whether there were significant differences between intervention and control beer halls at baseline. These included demographic characteristics, alcohol dependency (CAGE score), and HIV-risk related behaviors. In the post-intervention assessment, we assessed the reach, intensity, and impact of the intervention activities between the intervention and control beer halls. Our primary a priori hypothesis for the impact of the intervention, and the basis of our sample size and power estimation, was that the intervention could achieve a $40 \%$ lower number of episodes of unprotected sex with non-wife partners in the last 6 months among intervention beer hall patrons compared to control. Secondary outcomes included number of unprotected sexual episodes with specific partner types (including steady, casual, one off, and commercial sex partners), numbers of these different partner types, unprotected sex while intoxicated at last episode of sex with each partner type, abstaining from any sex, being faithful to one's wife (among married men), HIV/AIDS knowledge, and testing for HIV.

Additional analyses were done to explore for further evidence of an intervention effect. We assessed whether there were significant changes in risk behaviors from preto post-intervention waves in each of the two study arms by subtracting the post-intervention level from the pre-intervention level for each beer hall and applying the sign rank test. We assessed whether certain prevention activities were associated with risk reduction in the intervention arm 
by conducting Pearson correlations between the levels of specific activities at the beer hall and the level of reported risk behaviors. Finally, we assessed the potential effect of alcohol dependency on the intervention's impact on risk behavior by stratifying three levels of CAGE scores (terciles of high, medium, low). All analyses were done using the SAS statistical package (SAS version 8.0; Cary, NC, USA).

\section{Results}

\section{Baseline Characteristics}

A total of 1,284 men from 40 beer halls were surveyed at baseline. This represented a participation rate of $78 \%$ of the patrons systematically intercepted on the randomly selected venue-day-time periods. As noted above, we then limited our study to those beer halls with the least amount of cross-patronage, selecting 24 beer halls out of the 40 total surveyed at baseline. At baseline, 725 men out of the initial total 1,284 surveyed were patrons of these 24 beer halls that were ultimately randomized to the intervention and control arms. Table 1 compares baseline characteristics of patrons at beer halls randomized to the intervention $(N=12)$ and control $(N=12)$ arms prior to prevention activities. There were no significant differences in demographic characteristics between intervention and control beer hall patrons, including age, income, education, residence, and marital status. Alcohol dependency measured by median CAGE scores was also comparable [median and inter-quartile range (IQR) for both, 1.9, 1.8-2.0]. Levels of HIV-risk related measures did not significantly differ between study arms at baseline; although median episodes of unprotected sex with commercial partners in the preceding 6 months were somewhat higher at intervention beer halls (median 1.5, IQR 0.1-2.8) compared to controls (median 0.2, IQR 0-0.5), a difference that achieved borderline significance $(P=0.10)$.

\section{Exposure to Beer Hall Prevention Intervention Activities}

The post-intervention assessment surveyed 1,217 men at the same 24 beer halls, comprising $76 \%$ of patrons systematically approached at the randomly selected venue-day-time periods. A high level of awareness of the prevention program was achieved at the intervention beer halls (Table 2) with little apparent cross-contamination with control beer halls. The median intervention beer hall had $60.2 \%$ (IQR $50.0-64.1 \%$ ) of the patronage being aware that at least one of their fellow patrons had been trained as a peer educator. The median control beer hall level for the same question was $2.3 \%$ (IQR $1.1-6.6 \%$ ). About half of the patronage at intervention beer halls could both recognize the studyspecific logo and correctly explain its meaning in terms of the beer hall intervention theme (median $50.9 \%$, IQR 41.5-56.1\%) compared to a median of $2.4 \%$ at control beer halls (IQR 1.9-7.0\%). Recall of exposure to other programspecific materials at the intervention beer halls ranged from a median of $0.7 \%$ for seeing the program banner, to $49.6 \%$ seeing stickers with intervention-themed HIV prevention messages, compared to a range of $0-6.2 \%$ for the same measures at control beer halls. As expected, high proportions of patrons at both intervention and control beer halls reported seeing HIV prevention posters displayed on the walls (74.2 vs. $65.5 \%$, respectively, $P=0.005$ ), as these were placed in both intervention and control beer halls. Acquiescence bias was low, based on report of exposure to fictional materials and activities, such as the presence of a condom dispenser (reported by virtually no one), prevention messages on beer mugs (also reported by virtually no one), and being provided HIV prevention information from bar tenders (median $0 \%$ in intervention and control beer halls). We found high reporting of only one false material-prevention messages painted on the walls (median $30.5 \%$ in intervention beer halls and $35.3 \%$ at controls).

Table 2 shows beer hall patrons' exposure to studyspecific prevention activities. Median attendance of a condom demonstration given by a peer educator was $38.1 \%$, HIV prevention videos were seen by $27.7 \%$, and $27.5 \%$ had seen a peer-led HIV/AIDS educational presentation. Somewhat lower penetration was achieved for attending a "quiz show" (median 12.6\%), drama (11.3\%), poetry reading $(11.1 \%)$, and musical performance $(5.2 \%)$. All of these exposure levels were significantly higher than reported by control beer hall patrons, where median reported exposures ranged from 0 to $8.5 \%$.

The uptake of the study intervention concept was assessed by several mediating variables that related to friends interacting with their friends around HIV risk, also shown in Table 2. The median number of persons the respondent personally knew who were trained as peer educators was nearly five at intervention beer halls (median 4.9, IQR 4.5-5.3) compared to two at control beer halls (median 2.0, IQR 0.5-3.4). Although this finding was significantly higher at intervention beer halls $(P=0.002)$, many control patrons did know persons trained as peer educators, though it was not clear whether these were the Sahwira intervention peer educators or beer hall patrons who had been trained elsewhere. When asked if they had friends in their immediate drinking circle who were trained as peer educators, the median number was higher $(P=0.02)$ at intervention beer halls (median 1.7, IQR 1.4-2.2) than at controls (median 0.3, IQR 0-1.3). Over three-quarters (median 77.0\%, IQR $74.0-83.3 \%$ ) of intervention beer hall patrons said that they 
Table 1 Pre-intervention (baseline) characteristics of male beer hall patrons by randomization assignment, Harare, Zimbabwe

\begin{tabular}{|c|c|c|c|}
\hline Measures (in last 6 months unless otherwise indicated) & Intervention beer halls $\left(\mathrm{IQR}^{\mathrm{a}}\right)$ & Control beer halls (IQR) & $P$ value $^{\mathrm{b}}$ \\
\hline Number of patrons surveyed & 363 & 362 & - \\
\hline \multicolumn{4}{|l|}{ Demographic characteristics } \\
\hline Median age (years) & $29.5(28.5-34.0)$ & $30.8(28.5-33.3)$ & 0.69 \\
\hline Median income in last 30 days ( $\mathrm{Z} \$$ thousand) & $240(200-300)$ & $275(225-300)$ & 0.30 \\
\hline O-level education (approximately 11th grade in the US) or more & $65.7(62.9-82.4)$ & $70.7(59.0-72.5)$ & 0.59 \\
\hline Spent last 12 months in Harare $(\%)$ & $83.3(76.7-91.4)$ & $88.8(84.0-91.0)$ & 0.31 \\
\hline Currently married $(\%)$ & $58.3(54.3-68.6)$ & $59.2(54.0-62.1)$ & 0.67 \\
\hline Alcohol dependency: CAGE score (range 0-4) & $1.9(1.8-2.0)$ & $1.9(1.8-2.0)$ & 0.40 \\
\hline \multicolumn{4}{|l|}{ HIV-risk related behavior } \\
\hline \multicolumn{4}{|l|}{ All sex partners } \\
\hline Mean number of partners & $1.5(1.3-1.7)$ & $1.5(1.3-1.7)$ & 0.64 \\
\hline Mean episodes of sex & $98.4(64.4-117.4)$ & $88.3(73.4-102.8)$ & 0.48 \\
\hline Mean episodes of unprotected sex & $92.8(49.9-104.8)$ & $81.3(61.3-91.4)$ & 0.64 \\
\hline Unprotected sex while intoxicated, last episode $(\%)$ & $20.7(16.7-25.7)$ & $19.5(16.5-22.3)$ & 0.60 \\
\hline \multicolumn{4}{|l|}{ Wives } \\
\hline Mean number of partners & $0.7(0.6-0.7)$ & $0.6(0.6-0.7)$ & 0.83 \\
\hline Mean episodes of sex & $82.8(45.4-101.7)$ & $76.8(51.0-86.9)$ & 0.83 \\
\hline Mean episodes of unprotected sex & $81.4(45.0-96.4)$ & $76.2(51.0-85.5)$ & 0.74 \\
\hline Unprotected sex while intoxicated, last episode (\%) & $18.8(16.1-20.6)$ & $18.4(15.2-22.1)$ & 0.99 \\
\hline \multicolumn{4}{|l|}{ All non-wife partners } \\
\hline Mean number of partners & $0.8(0.7-1.0)$ & $0.9(0.6-1.0)$ & 0.85 \\
\hline Mean episodes of sex & $18.1(11.3-24.3)$ & $11.8(8.6-16.9)$ & 0.12 \\
\hline Mean episodes of unprotected sex & $12.7(4.1-20.5)$ & $5.9(4.3-9.9)$ & 0.23 \\
\hline Unprotected sex while intoxicated, last episode (\%) & $10.1(4.2-11.8)$ & $7.5(4.1-9.2)$ & 0.56 \\
\hline \multicolumn{4}{|l|}{ Steady partners } \\
\hline Mean number of partners & $0.2(0.2-0.3)$ & $0.3(0.2-0.3)$ & 0.78 \\
\hline Mean episodes of sex & $7.1(1.9-9.6)$ & $4.5(1.9-7.6)$ & 0.56 \\
\hline Mean episodes of unprotected sex & $5.3(0.8-8.8)$ & $3.6(1.3-4.5)$ & 0.60 \\
\hline Unprotected sex while intoxicated, last episode (\%) & $1.8(0.0-3.1)$ & $0.5(0.0-2.5)$ & 0.72 \\
\hline \multicolumn{4}{|l|}{ Casual partners } \\
\hline Mean number of partners & $0.3(0.2-0.4)$ & $0.3(0.2-0.4)$ & 1.00 \\
\hline Mean episodes of sex & $5.8(3.2-8.3)$ & $4.9(2.5-6.5)$ & 0.41 \\
\hline Mean episodes of unprotected sex & $3.1(0.6-6.1)$ & $1.4(0.2-3.5)$ & 0.13 \\
\hline Unprotected sex while intoxicated, last episode (\%) & $3.3(2.8-4.2)$ & $2.7(0.0-6.0)$ & 0.93 \\
\hline \multicolumn{4}{|l|}{ One off partners } \\
\hline Mean number of partners & $0.3(0.2-0.4)$ & $0.3(0.2-0.4)$ & 0.34 \\
\hline Mean episodes of sex & $0.2(0-2.6)$ & $0.1(0-1.4)$ & 0.28 \\
\hline Mean episodes of unprotected sex & $0(0-0.1)$ & $0(0-0.1)$ & 0.48 \\
\hline Unprotected sex while intoxicated, last episode (\%) & $0(0-0)$ & $0(0-0)$ & 1.0 \\
\hline \multicolumn{4}{|l|}{ Commercial sex partners } \\
\hline Mean number of sex partners & $0.4(0.2-0.5)$ & $0.3(0.2-0.4)$ & 0.24 \\
\hline Mean episodes of sex & $3.1(1.5-5.1)$ & $1.1(0.6-2.3)$ & 0.08 \\
\hline Mean episodes of unprotected sex & $1.5(0.1-2.8)$ & $0.2(0-0.5)$ & 0.10 \\
\hline Unprotected sex while intoxicated, last episode $(\%)$ & $2.8(0.8-5.7)$ & $2.4(1.5-4.3)$ & 0.69 \\
\hline \multicolumn{4}{|l|}{ Additional HIV-related measures } \\
\hline Abstaining from sex $(\%)$ & $8.3(5.7-13.5)$ & $7.0(4.0-11.1)$ & 0.37 \\
\hline Being faithful to wife (\% of men with partner) & $60.0(54.2-68.8)$ & $59.7(51.7-69.6)$ & 1.00 \\
\hline HIV/AIDS knowledge score (of eight points possible), mean & $6.3(6.2-6.6)$ & $6.5(6.2-6.7)$ & 0.39 \\
\hline
\end{tabular}


Table 1 continued

\begin{tabular}{|c|c|c|c|}
\hline Measures (in last 6 months unless otherwise indicated) & Intervention beer halls (IQR $\left.{ }^{\mathrm{a}}\right)$ & Control beer halls (IQR) & $P$ value ${ }^{\mathrm{b}}$ \\
\hline Tested for HIV in last 6 months (\%) & $5.7(0-8.3)$ & $3.4(1.5-7.5)$ & 0.93 \\
\hline
\end{tabular}

A total of 725 patrons were surveyed at the 24 beer halls (of the initial 40) later included in the subsequent randomization; thus, the baseline wave includes fewer subjects than the post intervention survey waves

a IQR: Inter-quartile range of the 12 beer halls in each arm

b Wilcoxon rank sum test on the 12 versus 12 levels of the variable per beer hall

Table 2 Awareness of the HIV prevention program, exposure to program activities, and mediating variables among male beer hall patrons by randomization assignment, post-intervention survey, Harare, Zimbabwe

\begin{tabular}{|c|c|c|c|}
\hline Measures (percent unless specified) & Intervention beer halls $\left(\mathrm{IQR}^{\mathrm{a}}\right)$ & Control beer halls (IQR) & $P$ value $^{\mathrm{b}}$ \\
\hline Number of patrons surveyed & 640 & 577 & - \\
\hline \multicolumn{4}{|l|}{ Awareness of intervention program at beer halls } \\
\hline Saw HIV prevention posters on walls (not specific to intervention) & $74.2(71.6-76.3)$ & $62.5(56.4-71.8)$ & 0.005 \\
\hline Aware of a trained peer educator patron & $60.2(50.0-64.1)$ & $2.3(1.1-6.6)$ & $<0.001$ \\
\hline Recognized study logo and could explain its meaning & $50.9(41.5-56.1)$ & $2.4(1.9-7.0)$ & $<0.001$ \\
\hline Saw program stickers & $49.6(43.8-60.1)$ & $6.2(3.6-14.0)$ & $<0.001$ \\
\hline Saw program bunting & $36.8(32.2-41.6)$ & $2.6(0-8.2)$ & $<0.001$ \\
\hline Saw program bulletin board & $35.0(33.0-37.7)$ & $2.0(0-2.7)$ & $<0.001$ \\
\hline Saw prevention messages painted on walls (not part of intervention) & $30.5(19.2-37.0)$ & $35.3(21.7-52.0)$ & 0.09 \\
\hline Saw program banner & $0.7(0-1.8)$ & $0(0-0)$ & 0.10 \\
\hline Saw condom dispenser (not part of intervention) & $0(0-0)$ & $0(0-0)$ & 0.36 \\
\hline Saw prevention messages on beer mugs (not part of intervention) & $0(0-0)$ & $0(0-0)$ & 0.51 \\
\hline \multicolumn{4}{|l|}{ Exposure to prevention activities at beer halls } \\
\hline Attended peer condom demonstration & $38.1(33.0-46.1)$ & $8.5(2.2-13.3)$ & $<0.001$ \\
\hline Attended HIV prevention video & $27.7(22.7-35.3)$ & $2.4(0-4.7)$ & $<0.001$ \\
\hline Attended HIV/AIDS educational presentation & $27.5(18.6-29.3)$ & $2.1(0-2.7)$ & $<0.001$ \\
\hline Attended HIV “quiz show” & $12.6(7.1-14.2)$ & $0(0-0.8)$ & $<0.001$ \\
\hline Attended HIV-related drama & $11.3(10.0-19.1)$ & $0.8(0-2.3)$ & $<0.001$ \\
\hline Attended HIV-related poetry reading & $11.1(7.7-15.6)$ & $0(0-0.8)$ & $<0.001$ \\
\hline Attended HIV-related music performance & $5.2(4.2-11.1)$ & $0(0-0)$ & $<0.001$ \\
\hline Bartender advised to reduce alcohol use (not part of intervention) & $0(0-0)$ & $0(0-2.2)$ & 0.18 \\
\hline \multicolumn{4}{|l|}{ Mediating variables } \\
\hline Number of people you know trained as a peer educator (mean) & $4.9(4.5-5.3)$ & $2.0(0.5-3.4)$ & 0.002 \\
\hline Number of friends in drinking circle trained as a peer educator (mean) & $1.7(1.4-2.2)$ & $0.3(0-1.3)$ & 0.002 \\
\hline Helped a friend avoid HIV risk behavior & $77.0(74.0-83.3)$ & $72.2(64.3-75.9)$ & 0.02 \\
\hline Helped by a friend to avoid HIV risk behavior & $63.2(62.0-65.8)$ & $56.4(50.5-62.3)$ & 0.01 \\
\hline Engaged in an informal group discussion on HIV at beer hall & $62.9(51.7-65.2)$ & $48.4(43.9-52.1)$ & 0.004 \\
\hline Made agreement with a friend to reduce HIV risk & $45.8(40.2-52.9)$ & $41.5(30.9-56.4)$ & 0.47 \\
\hline Encouraged by a friend into HIV risk behavior & $23.1(16.8-26.7)$ & $23.2(16.9-29.2)$ & 0.71 \\
\hline Had one-on-one discussion on personal HIV risk behavior & $18.0(12.0-24.4)$ & $18.9(14.9-20.9)$ & 0.89 \\
\hline Encouraged a friend into HIV risk behavior & $10.4(9.3-11.9)$ & $9.3(8.2-19.1)$ & 0.84 \\
\hline
\end{tabular}

A total of 1,217 beer hall patrons were surveyed in the 24 beer halls included in the randomization

a IQR: Inter-quartile range of the 12 beer halls in each arm

b Wilcoxon rank sum test on the 12 versus 12 levels of the variable per beer hall

had helped a friend avoid HIV risk, significantly $(P=0.02)$ but not substantially higher than that reported by control beer hall patrons (median $72.2 \%$, IQR $64.3-75.9 \%$ ). Similarly, high proportions of intervention and control patrons reported being helped by a friend to avoid HIV risk (median 63.2 vs. $56.4 \%$, respectively, $P=0.01$ ). A higher proportion of 
intervention patrons also participated in informal group discussions on HIV at their beer halls compared to control patrons (median 62.9 vs. $48.4 \%$, respectively, $P=0.004$ ). However, no differences between intervention and control beer halls were seen in the proportion of patrons making an agreement with a friend to reduce their risk behavior (median 45.8 vs. $41.5 \%$, respectively, $P=0.47$ ), being encouraged into risk behavior by a friend (23.1 vs. $23.2 \%$, respectively, $P=0.71$ ), having a one-on-one discussion on personal risk behavior with a beer hall friend (18.0 vs. $18.9 \%$, respectively, $P=0.89$ ), or encouraging a friend to engage in risk behavior (10.4 vs. $9.3 \%$, respectively, $P=0.84$ ).

\section{Effects of the Intervention on Sexual Risk Behavior}

Overall, we found no evidence of an impact of the intervention as determined by difference between intervention and control beer hall patrons in reported risk behavior in the 6 months preceding the post-intervention assessment. Table 3 compares post-intervention sexual risk behaviors reported by intervention to those reported by control beer hall patrons.

For our primary endpoint, both intervention and control beer hall patrons reported approximately five episodes of unprotected sex with non-wife partners (median 5.4 vs. 5.1, respectively, $P=0.98$ ). Control beer hall patrons tended to report fewer (but not significantly fewer) episodes of unprotected sex than intervention beer hall patrons across most partner types, including wives (median 53.4 vs. 56.1, respectively, $P=0.75$ ), steady partners (1.1 vs. 2.5 , respectively, $P=0.44$ ), casual partners (1.0 vs. 1.5 , respectively, $P=0.44$ ), and combining all partner types (58.5 vs. 60.0, respectively, $P=0.62$ ). Episodes of unprotected sex with one-off partners and commercial sex partners were low in both study arms.

Apart from episodes of unprotected sex, there was no evidence that the intervention reduced other risks for HIV (Table 3). For example, there were no differences in number of sex partners in the preceding 6 months across any partner type, such as non-wife partners, steady partners, casual partners, one-off partners, or commercial partners. The percent of episodes of sex where a condom was used also did not differ by study arm for any partner type, nor did the proportion of patrons who reported having unprotected sex while intoxicated at last episode of sex. Additionally, abstaining from sex, being faithful to one's wife, HIV/AIDS knowledge, and having tested for HIV did not differ between intervention and control beer halls after implementation of the intervention.

Comparing changes from baseline to post-intervention, we found generally declining levels of risk behavior in both study arms (Table 4). There were significant reductions in numbers of non-wife partners (median beer hall change:
0.4 fewer partners, $P=0.02$ ) and in episodes of unprotected sex with non-wife partners (median change: 6.9 fewer episodes, $P=0.05$ ) in the intervention beer halls from pre- to post-intervention. No significant reductions were seen in these variables at the control beer halls. Reductions were also seen in the number of casual partners, episodes of unprotected sex with casual partners, and episodes of unprotected sex with commercial sex partners among patrons of the intervention beer halls. An increase in wives as partners was also observed among intervention beer hall patrons. Among control beer hall patrons, reductions were noted in episodes of unprotected sex with all partners, episodes of unprotected sex with wives and number of casual partners.

Further exploration of the data was conducted to assess if there were significant linear relationships between the intensity of exposure to the intervention and the reported levels of risk behavior. Correlations of the activities listed in Table 2 with levels of specific risk behavior outcomes listed in Table 3 did not find evidence of an effect beyond an expected number of associations that would occur by chance alone at a significance level of $P<0.05$. Moreover, the directions of correlations were both positive and negative, suggesting no overall trend connecting intensity of exposure with declining risk behavior.

Finally, we specifically tested the hypothesis that the intervention could have had a differential effect among those with or without alcohol dependency by stratifying the analysis on three levels of CAGE scores. There was no evidence the intervention had an effect on sexual risk behavior within any level of alcohol dependency.

\section{Discussion}

We conducted an RCT of a venue-based HIV prevention intervention focused on men's risk related to alcohol consumption, a hypothesized driver of HIV transmission in sub-Saharan Africa [32-34]. We successfully randomized drinking venues with only a small degree of crosscontamination between study arms. We developed a theory-driven, peer-led behavioral HIV prevention program and implemented it with a high degree of fidelity to the protocol, achieving good levels of intervention penetration and exposure among beer hall patrons. We measured intervention efficacy by analyzing extensive partner-bypartner sexual behavior data that allowed us to look at many permutations of sexual risk and the impact of the intervention on them. Unfortunately, we found no evidence that our intervention reduced HIV-risk related behavior among male beer hall patrons.

The primary aim of our intervention was to increase the frequency of peer-to-peer interpersonal interactions to 
reduce risk, such as personally intervening in a risk situation or making a plan with a peer to avert risk. The intervention achieved statistically significant, albeit modest, increases in these interactions but there was no association between these interactions and sexual risk-taking. After 15 months of targeting close circles of drinking friends to

Table 3 Post-intervention HIV-risk related behavior among male beer hall patrons by randomization assignment, Harare, Zimbabwe

\begin{tabular}{|c|c|c|c|}
\hline Measures (in last 6 months unless otherwise indicated) & Intervention beer halls $\left(\mathrm{IQR}^{\mathrm{a}}\right)$ & Control beer halls (IQR) & $P$ value $^{\mathrm{b}}$ \\
\hline Number of patrons surveyed & 640 & 577 & - \\
\hline \multicolumn{4}{|l|}{ All sex partners } \\
\hline Mean number of partners & $1.5(1.3-1.7)$ & $1.5(1.3-1.7)$ & 0.98 \\
\hline Mean episodes of sex & $64.8(60.4-79.7)$ & $63.6(60.9-78.4)$ & 0.93 \\
\hline Mean episodes of unprotected sex & $60.0(54.5-73.8)$ & $58.5(54.3-67.9)$ & 0.62 \\
\hline Unprotected sex while intoxicated, last episode (\%) & $23.4(18.9-27.4)$ & $22.4(17.225 .9)$ & 0.80 \\
\hline \multicolumn{4}{|l|}{ Wives } \\
\hline Mean number of partners & $0.7(0.6-0.7)$ & $0.6(0.6-0.7)$ & 0.40 \\
\hline Mean episodes of sex & $57.9(49.9-70.3)$ & $56.1(49.0-62.6)$ & 0.80 \\
\hline Mean episodes of unprotected sex & $56.1(49.0-69.4)$ & $53.4(47.7-60.8)$ & 0.75 \\
\hline Unprotected sex while intoxicated, last episode (\%) & $20.9(14.8-25.7)$ & $19.3(12.3-25.8)$ & 0.84 \\
\hline \multicolumn{4}{|l|}{ All non-wife partners } \\
\hline Mean number of partners & $0.8(0.7-1.0)$ & $0.9(0.6-1.0)$ & 0.80 \\
\hline Mean episodes of sex & $9.4(6.0-12.6)$ & $8.7(5.3-15.4)$ & 0.80 \\
\hline Mean episodes of unprotected sex & $5.4(2.7-6.7)$ & $5.1(1.3-7.9)$ & 0.98 \\
\hline Unprotected sex while intoxicated, last episode (\%) & $9.5(7.0-11.7)$ & $6.3(4.89 .7)$ & 0.24 \\
\hline \multicolumn{4}{|l|}{ Steady partners } \\
\hline Mean number of partners & $0.2(0.2-0.3)$ & $0.3(0.2-0.3)$ & 0.24 \\
\hline Mean episodes of sex & $3.8(2.5-4.8)$ & $3.9(2.0-7.3)$ & 0.98 \\
\hline Mean episodes of unprotected sex & $2.5(1.1-3.2)$ & $1.1(0.5-4.0)$ & 0.44 \\
\hline Unprotected sex while intoxicated, last episode (\%) & $4.2(1.7-4.9)$ & $4.4(1.1-4.9)$ & 0.93 \\
\hline \multicolumn{4}{|l|}{ Casual partners } \\
\hline Mean number of casual partners & $0.3(0.2-0.4)$ & $0.3(0.2-0.4)$ & 0.77 \\
\hline Mean episodes of sex & $3.3(1.9-5.0)$ & $3.1(1.3-4.8)$ & 0.71 \\
\hline Mean episodes of unprotected sex & $1.5(0.7-2.5)$ & $1.0(0.2-2.1)$ & 0.44 \\
\hline Unprotected sex while intoxicated, last episode (\%) & $3.9(2.4-6.2)$ & $2.7(2.0-4.6)$ & 0.16 \\
\hline \multicolumn{4}{|l|}{ One off partners } \\
\hline Mean number of partners & $0.3(0.2-0.4)$ & $0.3(0.2-0.4)$ & 0.89 \\
\hline Mean episodes of sex & $0(0-0.1)$ & $0.1(0-0.3)$ & 0.40 \\
\hline Mean episodes of unprotected sex & $0(0-0)$ & $0(0-0)$ & 0.55 \\
\hline Unprotected sex while intoxicated, last episode (\%) & $0(0-0)$ & $0(0-0)$ & 1.0 \\
\hline \multicolumn{4}{|l|}{ Commercial sex partners } \\
\hline Mean number of partners & $0.3(0.2-0.3)$ & $0.2(0.1-0.3)$ & 0.62 \\
\hline Mean episodes of sex & $1.2(1.0-2.3)$ & $1.6(0.7-2.8)$ & 0.93 \\
\hline Mean episodes of unprotected sex & $0.5(0.3-1.3)$ & $0.6(0.2-1.6)$ & 0.98 \\
\hline Unprotected sex while intoxicated, last episode (\%) & $3.8(1.3-5.2)$ & $1.9(0.9-4.1)$ & 0.26 \\
\hline \multicolumn{4}{|l|}{ Additional HIV-related measures } \\
\hline Abstaining from sex $(\%)$ & $6.8(5.7-9.8)$ & $7.8(4.9-9.9)$ & 0.95 \\
\hline Being faithful to wife (\% of men with partner) & $61.0(55.5-68.6)$ & $59.0(55.1-74.9)$ & 0.71 \\
\hline HIV/AIDS knowledge score (of 8 points possible), mean & $6.3(6.2-6.6)$ & $6.5(6.2-6.7)$ & 0.39 \\
\hline Tested for HIV in last 6 months $(\%)$ & $3.0(1.6-6.6)$ & $3.2(1.9-4.5)$ & 0.82 \\
\hline
\end{tabular}

A total of 1,217 beer hall patrons were surveyed in the 24 beer halls included in the randomization

${ }^{a}$ IQR: Inter-quartile range of the 12 beer halls in each arm

b Wilcoxon rank sum test on the 12 versus 12 levels of the variable per beer hall 
Table 4 Change in HIV-risk related behavior among male beer hall patrons by randomization assignment, pre- versus post-intervention, Harare, Zimbabwe

\begin{tabular}{|c|c|c|c|c|}
\hline Measures (in last 6 months) & $\begin{array}{l}\text { Change }^{\mathrm{a}} \text { at } \\
\text { intervention beer halls }\end{array}$ & $\begin{array}{l}P \text { value }^{\mathrm{b}} \text { for change at } \\
\text { intervention beer halls }\end{array}$ & $\begin{array}{l}\text { Change }{ }^{\mathrm{a}} \text { at control } \\
\text { beer halls }\end{array}$ & $\begin{array}{l}P \text { value }^{\mathrm{b}} \text { for change } \\
\text { at control beer halls }\end{array}$ \\
\hline \multicolumn{5}{|l|}{ All sex partners } \\
\hline Mean number of partners & -0.3 & 0.05 & -0.1 & 0.20 \\
\hline Mean episodes of unprotected sex & -11.8 & 0.08 & -15.0 & 0.007 \\
\hline \multicolumn{5}{|l|}{ Wives } \\
\hline Mean number of partners & 0.1 & 0.05 & 0 & 0.62 \\
\hline Mean episodes of unprotected sex & -5.3 & 0.24 & -17.3 & 0.02 \\
\hline \multicolumn{5}{|l|}{ All non-wife partners } \\
\hline Mean number of partners & -0.4 & 0.02 & -0.2 & 0.18 \\
\hline Mean episodes of unprotected sex & -6.9 & 0.05 & -1.7 & 0.27 \\
\hline \multicolumn{5}{|l|}{ Steady partners } \\
\hline Mean number of partners & 0 & 0.70 & 0 & 0.73 \\
\hline Mean episodes of unprotected sex & -2.9 & 0.12 & -1.1 & 0.23 \\
\hline \multicolumn{5}{|l|}{ Casual partners } \\
\hline Mean number of casual partners & -0.2 & 0.02 & -0.1 & 0.05 \\
\hline Mean episodes of unprotected sex & -0.8 & 0.05 & -0.3 & 0.34 \\
\hline \multicolumn{5}{|l|}{ One off partners } \\
\hline Mean number of partners & -0.1 & 0.12 & 0 & 0.73 \\
\hline Mean episodes of unprotected sex & 0 & 0.56 & 0 & 0.43 \\
\hline \multicolumn{5}{|l|}{ Commercial sex partners } \\
\hline Mean number of partners & 0 & 0.32 & 0 & 0.97 \\
\hline Mean episodes of unprotected sex & -0.6 & 0.05 & 0.5 & 0.15 \\
\hline
\end{tabular}

A total of 725 beer hall patrons at pre-intervention baseline and 1,217 at post-intervention were surveyed at the 24 beer halls included in the intervention

a Subtracting post-intervention level from pre-intervention level for each beer hall; negative numbers denote a reduction in risk behavior

b Sign rank test on the difference from pre- to post-intervention change

take responsibility for each other's sexual health, we found no differences in the median numbers of sexual partners of any type, median episodes of unprotected sex with partners of any type, abstaining from sex, being faithful, percent condom use, HIV/AIDS knowledge, or HIV testing compared to patrons receiving only general prevention messages. Further, we found no convincing correlations between the reach and intensity of specific prevention efforts and risk behavior in the intervention arm. Even the more conventional peer-education activities, such as condom demonstrations, group talks, and "edu-tainment" events were not associated with behavior change even though they were well-attended. Finally, we did not find evidence of an effect of the intervention among patrons according to their levels of alcohol dependency.

Significant reductions in some measures of risk from baseline to post-intervention were noted in the intervention arm; however, this finding should not be over-interpreted. General reductions in risk were also noted in the control arm over time and one measure of risk, unprotected sex with commercial partners, was somewhat higher at baseline in the intervention arm than in the control.
It is important to examine the possible factors that contributed to the fact that this intervention did not produce the intended effects. Of course, the role of chance in the detection of effects should be considered. Had any apparent effects been evident with the conservative approach of considering the beer hall the unit of analysis, we intended more complex analyses (e.g., GEE) to account for clustering and to adjust for any residual confounding. In the end, this was not warranted. Apart from the role of chance, we identify several design and theoretical issues to consider. First, it is possible our decision to use serial, crosssectional surveys weakened the study's capacity for causal inference as compared to intervention studies that follow individuals over time. Our decision to use cross-sectional samples and beer halls as the unit of statistical analysis, however, was based on the nature of the intervention, which sought to effect change among beer hall patrons at large through diffusion of innovation from a core group of peer educators through their friendship networks. In order to examine the efficacy of this type of friendship network intervention, spreading outward from those directly trained by the program, we believed cross-sectional surveys were 
the most appropriate evaluation strategy. Of note, cohort studies are subject to some biases avoided by crosssectional surveys, such as loss to follow-up and intervention effects from repeated contacts including multiple risk assessment surveys and HIV counseling and testing.

Second, it is possible the intervention implementation was insufficiently intense to achieve an effect. However, we implemented the intervention with high staff involvement, high levels of activity among the peer educators, multiple follow-up booster training sessions, and popularity of the intervention program among beer hall patrons. Still, given the social and economic upheaval that characterized the intervention period (mid-2005 to end of 2006) in Zimbabwe, questions remain concerning whether the intervention ever created sufficient intensity to produce measurable effects in a cross-sectional sample of beer hall patrons. For a period of 3 months, the Zimbabwean government conducted a so-called "clean up campaign" in Harare that included destruction of areas in the low-income neighborhoods where our study was conducted. We were forced to suspend the intervention activities for 2 months and to conduct intensive outreach to peer educators who had been displaced. While the majority of the trained Sahwira peer educators returned to the beer halls following the interruption, we acknowledge a period of lower intensity of the intervention. As noted in the methods, being a Sahwira peer educator did require a substantial time commitment in training, refresher courses, and facilitating activities and the voluntary nature of the program may have precluded sufficient exposure to the intervention. Of note, however, the central focus of the intervention effort was to influence the course of the usual socializing between friends at the beer halls and the visible intervention activities were meant to reinforce conversations between friends during their time together at the beer halls. Also affecting exposure to the intervention, inflation rose dramatically during the intervention period, resulting in fewer patrons attending the beer halls overall. The stress of economic decline may have also led to a decline in the salience of HIV prevention as an issue of importance among beer hall patrons. In addition, it is also possible that the men who benefited most from the intervention did not return to the beer halls as frequently and were therefore less likely to participate in the post-intervention assessment survey.

Third, our strategy for recruiting beer hall patrons to become peer educators was very inclusive, as we attempted to maximize transparency and minimize any possible tensions between cliques of drinking friends. While this strategy was successful in exceeding our recruitment expectations, it is possible that the beer hall patrons we recruited were not sufficiently influential in their social circles. Other studies have shown that when peer educators are popular opinion leaders (POLs) within their social networks, this may enhance their effectiveness [27, 28, 30, 44]. However, effective identification and recruitment of POLs can be difficult $[45,46]$ and our intervention sought to show whether a simpler recruitment strategy could be effective. Most importantly, our intervention was based upon the influence of close, intimate friends (sahwira), not upon generally popular persons.

Fourth, survey research activities at control beer halls necessarily included prevention information, including HIV prevention posters, condom advertisements, and condoms available for purchase. Subjects participating in the surveys also received HIV counseling and testing from trained counselors. In addition, as a service to all beer hall patrons, and at the request of the beer hall owners, our study team provided basic HIV prevention education inside of all beer halls during recruitment periods. Thus, all study participants received AIDS education services that exceeded the community standard-a factor that may have played an important role in the intervention outcomes and explain the generally declining levels of risk behavior in both study arms.

While several community-level, peer-oriented AIDS prevention interventions have proven effective in changing behavior [44, 47-49], the negative results reported here are echoed in other behavioral RCTs. The most pertinent comparison is the Community Popular Opinion Leader Intervention which employed a community-POL approach to HIV prevention in five countries, including Zimbabwe and India [50]. In Zimbabwe, the intervention was implemented at rural centers for commerce and entertainment that included concentrations of drinking places like beer halls. The India site was focused on wine shops which, like beer halls, are patronized primarily by men and serve as venues for male-male socializing. At all five sites, the intervention failed to produce greater behavioral risk and HIV/STD incidence reduction than comparison conditions [29]. In addition, the overall trend was for lower behavioral and biological risk in both control and intervention arms, with the most dramatic declines in the Indian wine-shop venues. The authors conclude that the extensive AIDS education received by participants in the comparison groups may explain the intervention's lack of effectiveness.

There are, therefore, important parallels between the findings of the community-POL study and our results. Both studies suggest that male drinking venues are viable intervention sites for engaging men in male peer education programs. However, in both studies there was evidence of behavioral risk reductions in both intervention and control arms, which casts doubt on the additional effectiveness of the POL intervention over and above more conventional AIDS education approaches in these settings.

Our RCT did not produce the results we hoped to see. The publication and careful examination of interventions 
with negative results is an important but difficult, and often avoided, part of the process to improve prevention approaches and the methods to evaluate them. Overall, our study indicates that a male peer education intervention can be implemented in beer halls with a high degree of fidelity to theory and protocol, and that men in alcohol consumption environments are very receptive to playing an active role in such programs. Our negative findings do not mean that such peer interventions cannot work but that we have not yet found the means of harnessing male bonding in ways that significantly reduce HIV-related risk behaviors. In our view, it remains an imperative to productively engage men in AIDS prevention broadly and, more specifically, to intervene in those processes where male bonding, alcohol consumption, and sexual risk behavior are intertwined. In many parts of Africa, drinking venues deserve further exploration as intervention sites and should be just one of many community-based strategies developed to involve heterosexual men in AIDS prevention in Africa and beyond.

Acknowledgments This research was supported by a grant from the National Institute on Alcohol Abuse and Alcoholism (AA13538-01). We would like to thank the beer hall patrons, managers and staff who generously gave their time to participate in this research and the beer hall corporate owner, Rufaro Marketing, for its kind cooperation. We would also like to thank the project staff members for their many years of dedicated service and the University of Zimbabwe-University of California, San Francisco Collaborative Research Programme on Women's Health for its administrative support.

Open Access This article is distributed under the terms of the Creative Commons Attribution Noncommercial License which permits any noncommercial use, distribution, and reproduction in any medium, provided the original author(s) and source are credited.

\section{References}

1. Dunkle K, Jewkes R. Effective HIV prevention requires gendertransformative work with men. Sex Transm Inf. 2007;83:173-4.

2. Foreman M. AIDS and men: taking risks or taking responsibility. London: Panos; 1999.

3. Gupta G. How men's power over women fuels the HIV epidemic. BMJ. 2002;324:183-4.

4. Mbizvo M, Bassett M. Reproductive health and AIDS prevention in sub-Saharan Africa: the case for increased male participation. Health Policy Plann. 1996;11:84-92.

5. Obbo C. HIV transmission: men are the solution. Popul Environ. 1993;14:211-43.

6. Rivers K, Aggleton P. Men and the HIV epidemic. Geneva: UNDP; 1999.

7. UNAIDS. Men and AIDS-a gendered approach. Geneva: UNAIDS; 2000.

8. Dunkle K, Jewkes R, Nduna M, et al. Perpetration of partner violence and HIV risk behavior among young men in the rural Eastern Cape, South Africa. AIDS. 2006;20:2017-114.

9. Halperin D, Epstein H. Concurrent sexual partnerships help explain Africa's high HIV prevalence: implications for prevention. Lancet. 2004;364:4-6.
10. Hunter M. Cultural politics and masculinities: multiple-partners in historical perspective in KwaZulu-Natal. Cult Health Sex. 2005;7:389-403.

11. Jewkes R, Dunkle K, Nduna M, et al. Factors associated with HIV sero-status in young rural South African women: connections between intimate partner violence and HIV. Int J Epidemiol. 2006;35:1461-8.

12. Maman S, Mbwambo J, Hogan N, et al. HIV-positive women report more lifetime partner violence: findings from a voluntary counselling and testing clinic in Dar es Salaam, Tanzania. Am J Public Health. 2002;92:1331-7.

13. Higgins J, Hoffman S, Dworkin S. Rethinking gender, heterosexual men, and women's vulnerability to HIV/AIDS. Am J Public Health. 2010;100:435-45.

14. Burton J, Darbes L, Operario D. 2008. Couples-focused behavioral interventions for prevention of HIV: systematic review of the state of evidence. AIDS Behav. 2010;141:1-10.

15. Dunkle K, Stephenson R, Karita E, et al. New heterosexually transmitted HIV infections in married or cohabiting couples in urban Zambia and Rwanda: an analysis of survey and clinical data. Lancet. 2008;371:2183-91.

16. Uganda AIDS Commission, UNAIDS. Uganda HIV prevention response and modes of transmission analysis. Kampala: Uganda AIDS Commission; 2009.

17. Wyrod R, Fritz K, Woelk G, Jain et al. Beyond sugar daddies: intergenerational sex and AIDS in urban Zimbabwe. AIDS Behav. 2010; Sep. 2 [Epub ahead of print].

18. Greig A, Peacok D, Jewkes R, et al. Gender and AIDS: time to act. AIDS. 2008;22:S35-43.

19. Peacock D, Levack A. The men as partners program in South Africa: reaching men to end gender-based violence and promote reproductive health. Int J Mens Health. 2004;3:173-88.

20. Pulerwitz J, Michaelis A, Verma R, et al. Addressing gender dynamics and engaging men in HIV programs: lessons learned from Horizons research. Public Health Rep. 2010;125:282-92.

21. Machekano R, McFarland W, Mbizvo M, et al. Impact of HIV counselling and testing on HIV seroconversion and reported STD incidence among male factory workers in Harare, Zimbabwe. Cent Afr J Med. 1998;44:98-102.

22. Pulerwitz J, Widyono M, Mehta M, et al. Promoting gender equity for HIV and violence prevention: results from the PEPFAR male norms initiative evaluation in Namibia. Washington, DC: PATH; 2010.

23. Pulerwitz J, Martin S, Mehta M, et al. Promoting gender equity for HIV and violence prevention: results from the male norms initiative evaluation in Ethiopia. Washington, DC: PATH; 2010.

24. Kimmel M. Masculinity as homophobia: fear, shame, and silence in the construction of gender identity. In: Brod H, Kaufman M, editors. Theorizing masculinities. London: Sage; 1994. p. $119-41$.

25. Flood M. Men, sex, and homosociality: how bonds between men shape their sexual relations with women. Men Masc. 2008; 10:339-59.

26. Smith D. Love and the risk of HIV: courtship, marriage, and infidelity in southeastern Nigeria. In: Hirsch J, Wardlow H, editors. Modern loves: the anthropology of romantic courtship \& companionate marriage. Ann Arbor: University of Michigan Press; 2006. p. 135-56.

27. Kelly J, Murphy D, Sikkema K, the Community HIV Prevention Research Collaborative, et al. Randomized, controlled, community level HIV prevention intervention for sexual risk behaviour among homosexual men in U.S. cities. Lancet. 1997;350: $1500-5$.

28. Jones K, Gray P, Whiteside Y, et al. Evaluation of an HIV prevention intervention adapted for Black men who have sex with men. Am J Public Health. 2008;98:1043-50. 
29. NIMH Collaborative HIV/STD Prevention Trial Group. Results of the NIMH collaborative HIV/sexually transmitted disease prevention trial of a community popular opinion leader intervention. J Acquir Immune Defic Syndr. 2010;54:204-14.

30. Sikkema K, Kelly J, Winett R, et al. Outcomes of a randomized community-level HIV prevention intervention for women living in 18 low-income housing developments. Am J Public Health. 2000;90:57-63.

31. Bassett M, McFarland W, Ray S, et al. Risk factors for HIV infection at enrollment in an urban male factory cohort in Harare, Zimbabwe. J Acquir Immune Defic Syndr. 1996;13:287-93.

32. Fritz K, Woelk G, Bassett M, et al. The association between alcohol use, sexual risk behavior, and HIV infection among men attending beerhalls in Harare, Zimbabwe. AIDS Behav. 2002;6: 221-8.

33. Fritz K, Morojele N, Kalichman S. Alcohol: the forgotten drug in HIV/AIDS. Lancet. 2010;376:398-9.

34. Kalichman S, Simbayi L, Kaufman M, et al. Alcohol use and sexual risks for HIV/AIDS in sub-Saharan Africa: systematic review of empirical findings. Prev Sci. 2007;8:141-51.

35. Lewis J, Garnett G, Mhlanga S, et al. Beer halls as a focus for HIV prevention activities in rural Zimbabwe. Sex Transm Dis. 2005;32:364-9.

36. UNAIDS. Global Report: UNAIDS Report on the global AIDS epidemic. Geneva: UNAIDS; 2010.

37. Kanouse D, Berry S, Duan N. Drawing a probability sample of female street prostitutes in Los Angeles County. J Sex Res. 1999;36:45-51.

38. MacKellar D, Gallagher K, Finelayson T, et al. Surveillance of HIV risk and prevention behaviors of men who have sex with men - a national application of venue based, time-space sampling. Public Health Rep. 2007;122:S39-47.

39. Magnani R, Sabin K, Saidel T, et al. Review of sampling hard-toreach and hidden populations for HIV surveillance. AIDS. 2005;19:S67-72.
40. Fisher J, Fisher W. Changing AIDS-risk behavior. Psychol Bull. 1992;111:455-74.

41. Fisher J, Fisher W, Williams S, et al. Empirical tests of an information-motivation-behavioral skills model of AIDSpreventive behavior with gay men and heterosexual university students. Health Psychol. 1994;13:238-50.

42. Bertrand J. Diffusion of innovations and HIV/AIDS. J Health Commun. 2004;9:113-21.

43. Rogers E. Diffusion of innovations. 4th ed. New York, NY: Free Press; 1995.

44. Kelly J, St Lawrence J, Diaz Y, et al. HIV risk behavior reduction following intervention with key opinion leaders of population: an experimental analysis. Am J Public Health. 1991;81:168-71.

45. Elford J, Bolding G, Sherr L. Popular opinion leaders in London: a response to Kelly. AIDS Care. 2004;16:151-8.

46. Kelly J. Popular opinion leaders and HIV prevention peer education: resolving discrepant findings, and implications for the development of effective community programmes. AIDS Care. 2004;16:1-12.

47. CDC AIDS Community Demonstration Projects Research Group. Community-level HIV intervention in five cities: final outcome data from the AIDS community demonstration projects. Am J Public Health. 1999;89:336-45.

48. Kegeles S, Hays R, Coates T. The Mpowerment Project: a community-level HIV prevention intervention for young gay men. Am J Public Health. 1996;86:1129-36.

49. Lauby J, Smith P, Stark M, et al. A community-level prevention intervention for inner city women: results of the Women and Infants Demonstration Projects. Am J Public Health. 2000;90: 216-22.

50. NIMH Collaborative HIV/STD Prevention Trial Group. Selection of populations in the NIMH collaborative HIV/STD prevention trial. AIDS. 2007;21:S19-28. 